\title{
A Web-based DSS: Information System for Sustainable Fisheries Supply Chain in Coastal Communities of Small Islands Indonesia
}

\author{
Wellem Anselmus Teniwut ${ }^{\mathrm{a},}{ }^{,}$, Cawalinya Livsanthi Hasyimª, Dawamul Arifin ${ }^{\mathrm{b}}$ \\ ${ }^{a}$ Fisheries Agribusiness Study Program, Tual State Fisheries Polytechnic, Southeast Maluku Regency, Indonesia \\ ${ }^{b}$ Geomatic Technology Study Program, Samarinda State Polytechnic of Agriculture, Samarinda, Indonesia \\ Corresponding author: ${ }^{*}$ wateniwut@polikant.ac.id
}

\begin{abstract}
Recent advances in the development of information technology and the rapid use of decision support systems play significant roles in various fields, including the fisheries sector. Fishery-based activity for small island regions created more complicated problems that limited marine resources and high production costs. Thus, the need to develop efficient and effective tools for interconnecting supply and production becomes more crucial than ever to help local coastal communities. This study aimed to designs a web-based DSS for a sustainable supply chain of sectors in Southeast Maluku Regency, Indonesia (SIRIPIKAN). Firstly, we crafted the DSS framework to identify the fishing, supplier, and seller locations. Secondly, we measured the level of sustainability of marine resources. Thirdly, the web-based DSS can help local coastal communities increase managers' capability and ability in the fisheries-related business activity carried out. SIRIPIKAN aims to increase the profitability of fisheries business activities in coastal communities and preserve marine resources. This research combined the data mining activities with spatial analysis to obtain the cluster support map and MSY to measure sustainability and feasibility study as an approach for the development of the system. The model provides an integrated sustainable production with users' input used to optimize the decision-making process of profitability and sustainability in existing marine resources.
\end{abstract}

Keywords -DSS; sustainable; SIRIPIKAN; supply chain; fisheries.

Manuscript received 7 Jul. 2020; revised 2 Dec. 2020; accepted 24 Feb. 2021. Date of publication 30 Jun. 2021. IJASEIT is licensed under a Creative Commons Attribution-Share Alike 4.0 International License.

\section{INTRODUCTION}

Information technology enables the modern business to have an extensive cooperation network, allowing them to compete and survive in a highly competitive environment, mainly when dealing with uncertain situations [1] [2]. One of the methods used to improve network cooperation is sharing information held by each business at the supply chain level. This process enables each party to make better decisions on the number of product requests, allocation of resources related to planning, and production costs, which produces dynamic supply chain relationships and impacts the level of profitability generated [3]. One of the causes of delay and disruption in the supply chain is inequality of information due to decentralization [4] and fisheries business activities where tons of moving parts and natural environment are hard to predict [5].

One of the causes of a decline in seaweed production in the Southeast Maluku Regency was the uneven distribution of information in its supply chain. [8] One of the limitations of the aquaculture business in coastal communities is the access and use of the latest relevant technology in the production process [6], [7]. The socio-economic factors such as potential conflicts also affect the sustainability of aquaculture businesses that are more efficient with optimal benefits [9]. The Maluku region's capture fisheries tend to experience a downward trend, irrespective of using an effective planning process [10].

Therefore, it is crucial to be immediately addressed in order to improve the welfare of coastal communities. The Information Communication Technology (ICT) facilities in Southeast Maluku Regency and the Internet need to be evenly distributed according to the region's geographical conditions which can significantly assist in analyzing and accuracy processes of fisheries data in the region. Therefore, the mining process is used to improve the data's contribution accuracy and applied in various fields [11], including the fisheries supply chain.

The supply chains play an important role in businesses' success with the intra and inter-sectoral parties used for performance sustainability. Every echelon needs to use its 
supply chain to increase its product's competitive intensity to the market [12]. Collaboration and integration in the supply chain strengthen networks and improve services to consumers. However, it is difficult to determine the constraints associated with stakeholders' willingness to share information, industry characteristics, and business type [13]. The development of information technology has led to a rapid increase in the transmission of information irrespective of distance and time. This development also positively impacted networking, connectivity, and the development of unlimited Intra and inter-businesses. Furthermore, globalization also increases business competitiveness which makes coordination between parties involved very crucial. Therefore, the information shared amongst parties in the supply chain is sensitive yet con contribute and highly related to production costs [14].

In a supply chain consisting of many independent actors, there is a higher likelihood of conflict because each entity has a different purpose. However, this condition is avoided when the flow of information circulating in the supply chain runs smoothly and which automatically forms a supply chain that is more likely to be a centralized planner [15]. Besides, previous studies have suggested factors that encourage sellerbuyer relationships for flexibility, as well as discounts in product quantity [16], [17], and payment options [18].

A web-based decision support system, also known as Intelligent DSS, is designed and built using several techniques and modeling methods. It uses one or more artificial intelligence-based methods, such as Artificial Neural Networks, Evolutionary Computing, Fuzzy Systems, CaseBased Reasoning, and Agent-Based Systems [19]. Various studies have been carried out to build a DSS-based supply chain system in various fields. For instance, the DSS supply chain using in the rubber industry was examined [20], while aluminum mining sites in India were developed [21]. Besides, another study [22] showed the use of DSS in supply chain petroleum.

Besides using DSS for supply chains, it has also been carried out with the data mining approach [23] and the application of spatial analysis in the supply chain [24]. Furthermore, the fuzzy analysis was adopted [25], while an agent-based approach was used [26].

The development of information technology and its level of utilization are becoming more widespread and an integral part of a business or industry. The use of the internet and websites in supporting supply chain activities has become more prevalent, especially in facilitating business actors in the decision-making process [27], [28]. The purpose of using the website in making a supply chain decision is to promote various factors such as the government, farmers, distributors, importers, and exporters. Using the right information accelerates the business flow [29], thereby improving the supply chain's performance. The purpose of using websites and the internet in forming a DSS system is to facilitate access [30], where it also improves the adaptability of existing DSS platforms to various operating systems and website algorithms [31]. Therefore, websites and the internet as a DSS container become increasingly essential and imperative due to the speed of information, availability, and ability to improve the supply chain performance.

It is necessary to have a system that makes it easy for every business in the supply chain of fisheries to optimize profits and streamline production costs. Therefore, this research aims to build a web-based fishery supply chain information system, using data mining and Spatial Analysis approaches. We expect that the system can improve the fisheries sector's performance in decision making, which is expected to increase the efficiency of production activities and improve the consistency of the profits obtained by the fisheries actors.

\section{MAteriAl AND Method}

\section{A. System Overview}

The development of SIRIPIKAN consists of four stages. The first is a field survey on the existing weaknesses inherent in the fisheries supply chain in Southeast Maluku Regency. The preliminary studies showed that the main weakness is related to product availability inconsistency due to production management, marketing, and buyers' capacity. It is also related to the location of fishing and cultivation, as shown in Figure 1.

The second stage is the literature review on the fishery supply chain system, which is carried out to identify further the systems in line with the needs of fisheries business operators in this region, such as infrastructure conditions. This stage aims to identify the concepts and models of DSS applicable to fisheries supply chains in areas with archipelagic characteristics, including types of data input, user, and data combinations. In this stage, a suitable system capable of coping with the production, managerial, post-production, and marine resources sustainability of fisheries is obtained, as shown in figure 2.

The third stage focuses on collecting spatial data needed by the system, which were obtained and processed using the mining method. This process aims at clustering producers, suppliers, and sellers of capture fisheries and aquaculture in this region, which are further processed with GIS to obtain location map output. For the managerial process, data collection is carried out by surveying the needs and items for production and post-production to marketing for the next process. The feasibility study concept is used to calculate the cost of production, marketing, and benefits obtained with the conditions of the origin, production, path, and means of distribution. For the sustainability of marine resources, field sufficiency was used to calculate the MSY (Maximum Sustainable Yield) concept. In contrast, the spatial analysis with the temperature and chlorophyll-a approach was used to determine the fishing locations. 


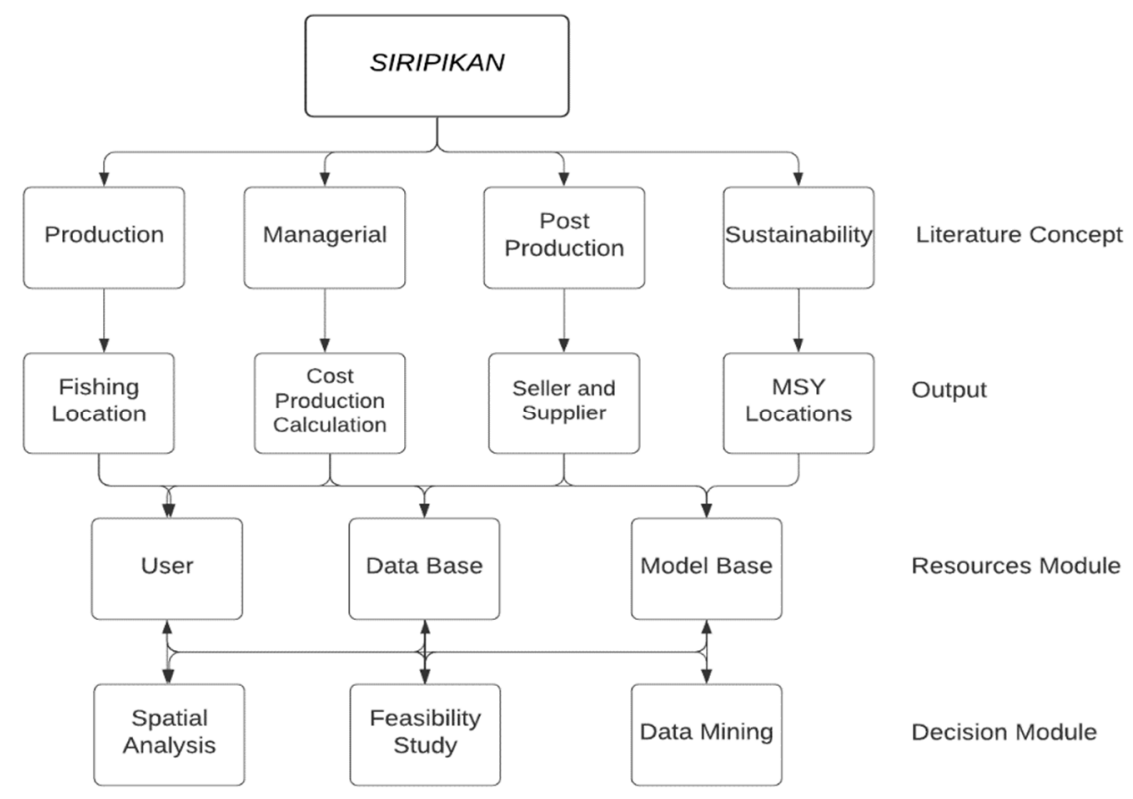

Fig. 1 Proposed system

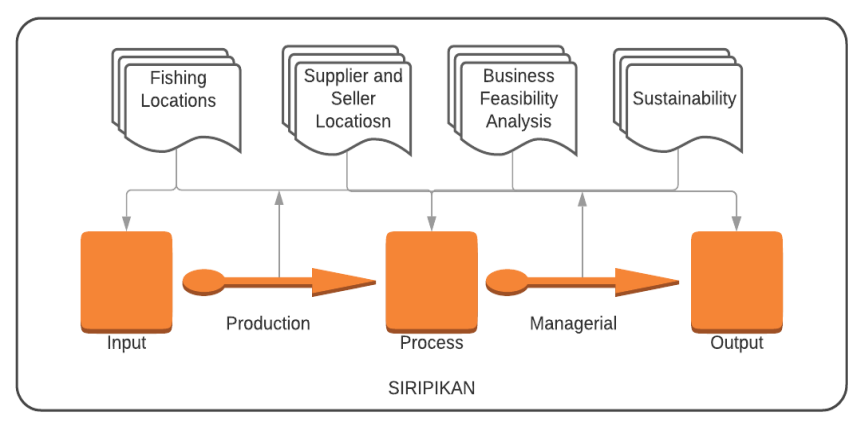

Fig. 2 System component and hierarchy architecture

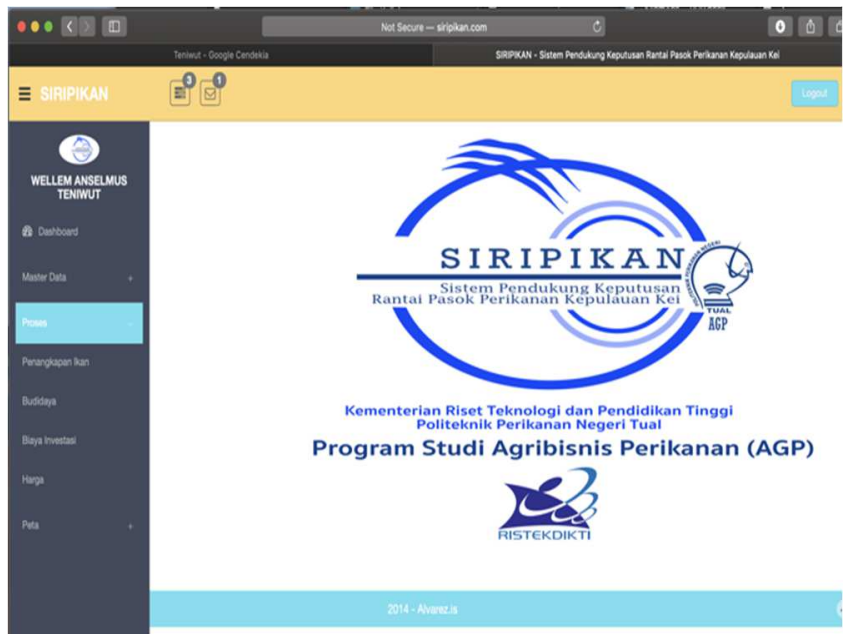

Fig. 3 SIRIPIKAN User interface

The fourth stage is to build a decision support system known as DSS SIRIPIKAN using a MySQL database, HTML, CSS, JavaScript, and PHP. The application is in beta at http://siripikan.com/public. MySQL was chosen to store basic data such as sub-districts, villages, equipment used, as well as production, distribution, and location costs. The web interface is built and managed using HTML and CSS, with JavaScript used to place sub-modules for users to input data into the MySQL database and then carry the output to the server. Data is processed in PHP to be stored again in MySQL.

\section{B. User interface}

The user interface is shown in Figure 3. Users are asked to input their original location, which is followed by choosing the fisheries sector. This category comprises two choices, namely the capture fisheries and aquaculture sectors. Furthermore, users are allowed to estimate the overall production costs by entering the distribution, production equipment, material, and marketing costs. For the types of production and transportation equipment sales, the production items are selected from the dropdown menu, which the admin can update.

\section{Fishing location}

The sea surface temperature distribution (SST) and chlorophyll-a approach were used to select fishing locations. For image data processing, the MODIS algorithm for chlorophyll-a was calculated based on Algorithm Theoretical Basic Document Modis 19 (ATBD 19) by [32] as shown in equation 1.

$$
\begin{gathered}
\log \operatorname{chl} a_{e m p}={ }_{c_{o}}+{ }_{c 1} \log _{(r 35)}+{ }_{c 2}\left[\log _{(r 35)}\right]^{2} \\
+{ }_{c 3}\left[\log _{(r 35)}\right]^{3}
\end{gathered}
$$

Where

$$
r_{35}=\frac{R_{r s}(488)}{R_{r s}(451}
$$

For SST, the Algorithm Theoretical Basic Document Modis 25 (ATBD 25) [33] was used as shown in equation 2.

$$
\begin{aligned}
& S S T \\
& =c_{1}+c_{2} *\left(T_{31}+273\right)+c_{3} *\left(T_{31}-T_{32}\right) \\
& *\left(T_{20}-273\right)+C_{4} *\left(T_{31}-T_{32}\right) \\
& *\left(\frac{1}{\cos \theta-1}\right)
\end{aligned}
$$


Where:

$\mathrm{T}_{20}$ is the brightness level of the temperature band 20 (BT)

$\mathrm{T}_{31}$ is the brightness level of the temperature band 31 (BT)

$\mathrm{T}_{32}$ is the brightness level of the temperature band 32 (BT)

$\mathrm{c}_{1}, \mathrm{c}_{2}, \mathrm{c}_{3}$, and $\mathrm{c}_{4}$ are the sea surface temperature coefficient, while $\theta$ is the satellite's zenith angle.

TABLE I

COEFFICIENTS FOR THE MODIS BAND 31 AND 32 SST RETRIEVAL ALGORITHMS DERIVED USING RADIOSONDES ATMOSPHERIC PROPERTIES AND VARIABILITY

\begin{tabular}{ccc}
\hline Coefficient & $\mathbf{T}_{\mathbf{3 1}}-\mathbf{T}_{\mathbf{3 2}}<=\mathbf{0 . 7}$ & $\mathbf{T}_{\mathbf{3 1}}-\mathbf{T}_{\mathbf{3 2}} \boldsymbol{> 0 . 7}$ \\
\hline $\mathrm{c}_{1}$ & 1,228552 & 1,692521 \\
$\mathrm{c}_{2}$ & 0,9576555 & 0,9558419 \\
$\mathrm{c}_{3}$ & 0,1182196 & 0,0873754 \\
$\mathrm{c}_{4}$ & 1,774631 & 1,199584 \\
\hline
\end{tabular}

The Planck inverse function equation was used to convert the water brightness temperature as shown in equation 3 .

$$
T_{b} \lambda=\frac{C_{2}}{\left[\lambda \ln \left(\frac{C_{1}}{\lambda^{5} \pi L_{\lambda}}+1\right)\right]}
$$

Where $T b$ is water brightness temperature $\left({ }^{0} \mathrm{~K}\right) . C_{1}$, $C_{2}$ is a constant number, where $C_{1} 1,1910659 * 10^{8}$ [W $\left.\mathrm{m}^{2} \mathrm{sr}^{-1}\left(\mu \mathrm{m}^{-1}\right)^{-4}\right]$, and $C_{2}$ is $1,438833 \times 10^{4}[\mathrm{~K} \mathrm{\mu m}], \gamma$ wavelength $(\mathrm{m})$, and $L$ is spectral radians $\left(W m^{-2} m^{-1} s t r^{-1}\right)$.

\section{Supplier locations}

The X-Means clustering approach, an extended K-Means, was used to select the potential supplier locations. X-Means tries to automatically determine the number of clusters based on Bayesian Information Criterion scores. The algorithm starts after each time the K-Means is run to make local decisions on the current centroid subset, which is a split to fit with the data [34]

\section{E. Sustainability Marine Resources}

The Gordon-Schaefer model was used to measure the maximum sustainable yield of water areas in each district. MSY value calculation was carried out using the concept of effort and yield with the value used to obtain the CPUE (catch per unit effort). Furthermore, the MSY value was obtained by calculating the optimal effort and predicted yield compared to the actual effort. The water area can be utilized as a fishing site, assuming the optimal effort value is lower than the actual.

$$
\text { CPUE }=\text { Catch } / \text { Effort }
$$

\section{F. Business Feasibility}

A business feasibility study is a research carried out to determine the feasibility of running a business, using various types of controls and operational activities to achieve goals and maximum profits. Some of the methods used in business feasibility studies are total cost, revenue, BEP, gross and net profits.

$$
\begin{gathered}
\text { Profit/Loss }=T R-T C \\
B E P=1\left(\frac{\frac{F C}{V C}}{S}\right)
\end{gathered}
$$

Where TR is total revenue calculated by multiply price and quantity production; TC is the total variable (VC) and fix cost (FC); $\mathrm{S}$ is sales volume, and BEP is the breakeven point.

\section{G. Preparation and Implementation}

The data collection process is divided into two main parts. First, the actual field data collection. This section collects data by carrying out factual verification on the coordinate points and water conditions by conducting in situ samplings. The goal is that we can obtain data on fishing locations, real conditions, and marine indicators. The second is data collection on fisheries business actors. This section uses direct survey techniques with questionnaires and Focus Group Discussions (FGD) with fishery business actors in this area. The goal is that we can obtain and verify fishing locations, identify production items, distribution, and sales to consumers. By doing so, we can obtain the data needed to run this SIRIPKAN application.

The fisheries supply chain information system (SIRIPIKAN) is carried out in Southeast Maluku District, Indonesia. This region is one of the archipelagic regions in the southeastern part of Maluku Province, which is located at the coordinate position of $131^{\circ}-133^{\circ} 5$ 'East Longitude and $5^{\circ}$ $-6.5^{\circ}$ South Latitude. Most of the villages in this region are located in the coastal area. This has made the fisheries sector primary support for the coastal communities' local economy in this region. Based on the regional, social and economic characteristics, the SIRIPIKAN application is carried out in this area and not in the Tual City area which is also located in the Kei Islands area.

\section{RESULT AND DISCUSSION}

In figure 4 , shows the mapping analysis of potential fish locations based on chlorophyll-a and SST. A description of the potential fishing locations in this area aims at facilitating their activities. Knowledge of the fishing location is also expected to increase the number of catches and level of profits due to the rise in the effectiveness of fishing activities.

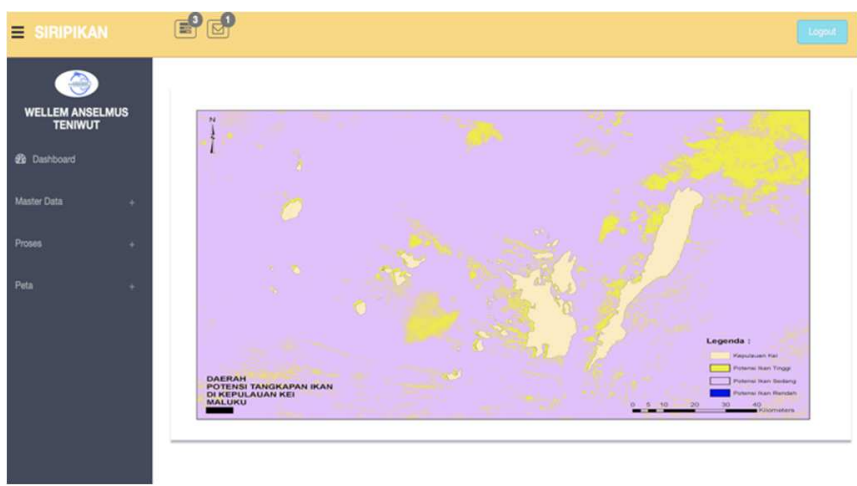

Fig. 4 Potential fish locations

Furthermore, table 2 shows the fisheries supplier data results in this region using the x-means clustering method based on the number of sellers, price criteria, and potential supplier locations. The criteria of the number of sellers and the selling price are used to determine locations with a significant number of buyers consistent with prices, as shown in figure 5 . Therefore, it is expected to facilitate fishermen in selling their catches and smoothly supply the upstream supply chain of fisheries commodities. 
TABLE II

Clustering Region BASED ON NuMBer of SEllers AND PRICE

\begin{tabular}{llc}
\hline No & Clusters & Value \\
\hline \multicolumn{3}{c}{ Number of sellers } \\
1 & Cluster 0 & $31.04 \%$ lower \\
2 & Cluster 1 & 32.14 lower \\
3 & Cluster 2 & $115.8 \%$ higher \\
4 & Cluster 3 & $128.9 \%$ hinger \\
& & Price \\
1 & Cluster 0 & - \\
2 & Cluster 1 & - \\
4 & Cluster 2 & $129.86 \%$ \\
4 & Cluster 3 & $73.1 \%$ lower \\
\hline
\end{tabular}

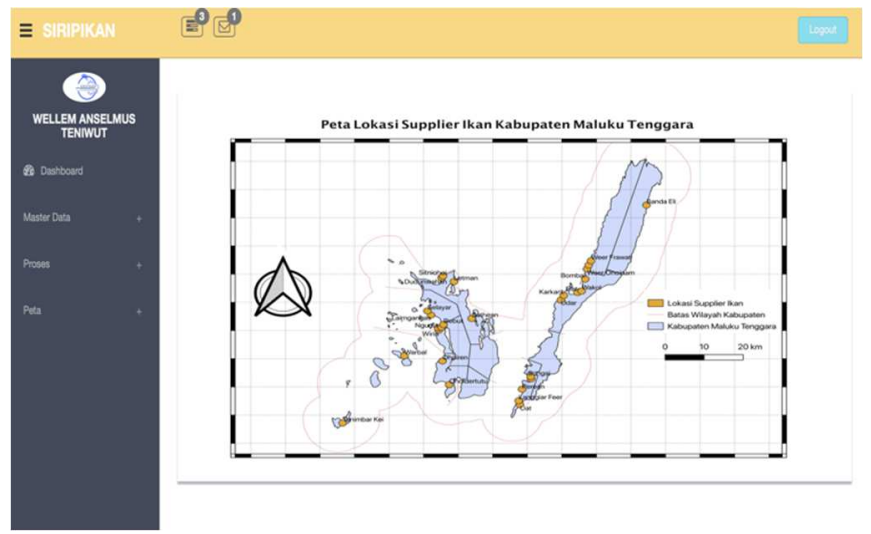

Fig. 5 Supplier locations for fisheries commodity

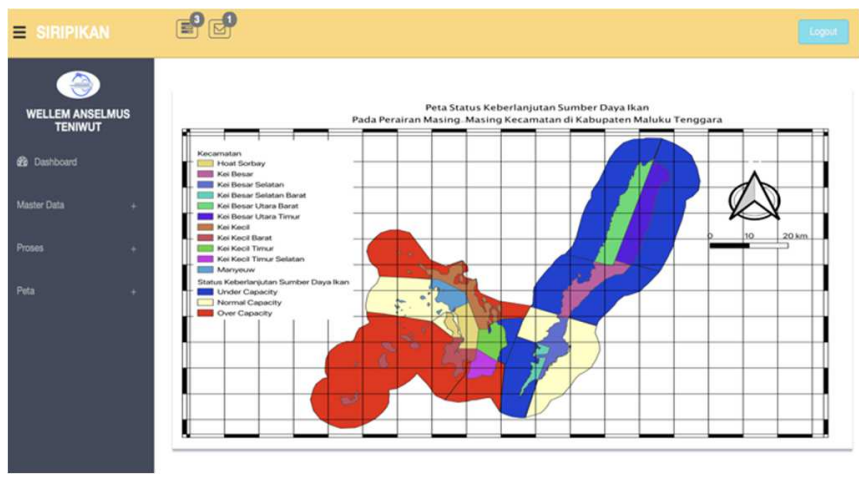

Fig. 6 Sustainability location of water in Southeast Maluku Regency

Furthermore, figure 6 shows the use of the CPUE approach and the MSY results in figure 7 to maintain marine resources' sustainability in this region. Waters were located in full capacity in untouched and well-utilized areas. Therefore, fishermen are expected to pay attention to this matter and maintain the sustainability of marine resources and increase the potential income earned.

Based on the simulation results conducted on capture fisheries activities in the village of Sathean, District of Kei Kecil, the amount of income and costs incurred as shown in Figure 8. Decision support systems in fisheries activities are increasingly being used in various regions of the world [35] [36]. With current developments in technology and information systems which are also supported by the expansion of the internet network, the role of DSS has become increasingly versatile. The increasingly widespread internet network in Southeast Maluku Regency's coastal areas makes SIRPIKAN's role very important and crucial in supporting the performance of fisheries business run by fishermen and cultivators in this region. SIRIPIKAN is built based on field studies' results and customized to fishery business actors' empirical needs. Based on the results of the field trials carried out, the validation of SIRIPIKAN performance results is also obtained, supported by the user's SIRIPIKAN prototype performance.

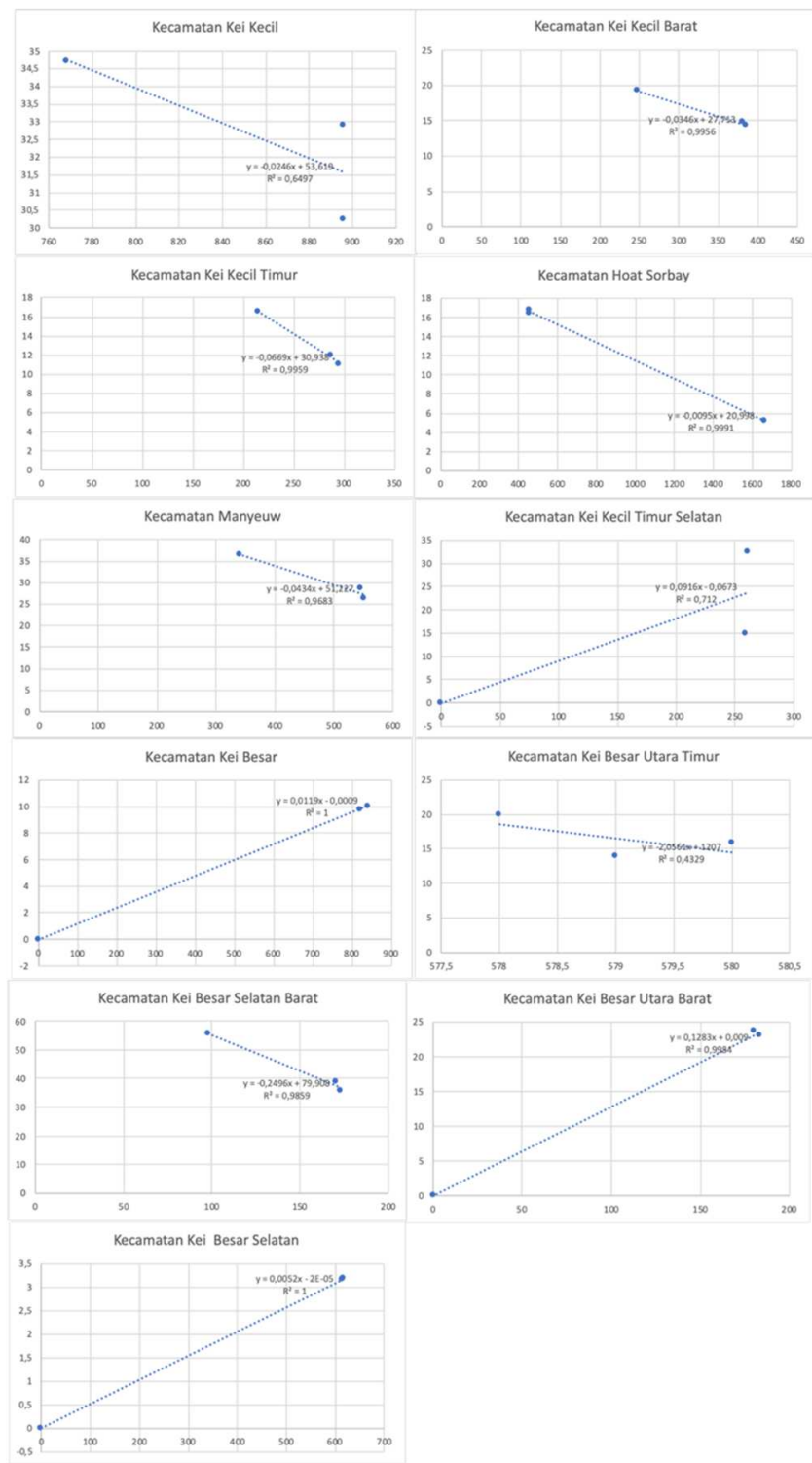

Fig. 7 MSY Result

SIRIPIKAN helps users in overcoming problems related to production consistency. Using SIRIPIKAN, based on field trials results by users who are catch fishermen, they have succeeded in verifying the fishing location, which has been their catching location and new locations that fishermen did not previously know. This new fishing location is near the fishing village, so it does not increase the fishing costs incurred. SIRIPIKAN also provides the location of the supplier closest to the fishing village's location to facilitate the process of selling fish by fishermen to get optimal cost efficiency. At SIRIPIKAN, users can also calculate the planning of production costs incurred and profit projections by fishery business actors in this area. Thus, SIRIPIKAN is able to improve managerial capabilities, increase the level of 
production cost efficiency to increase the fisheries operational performance of the users.
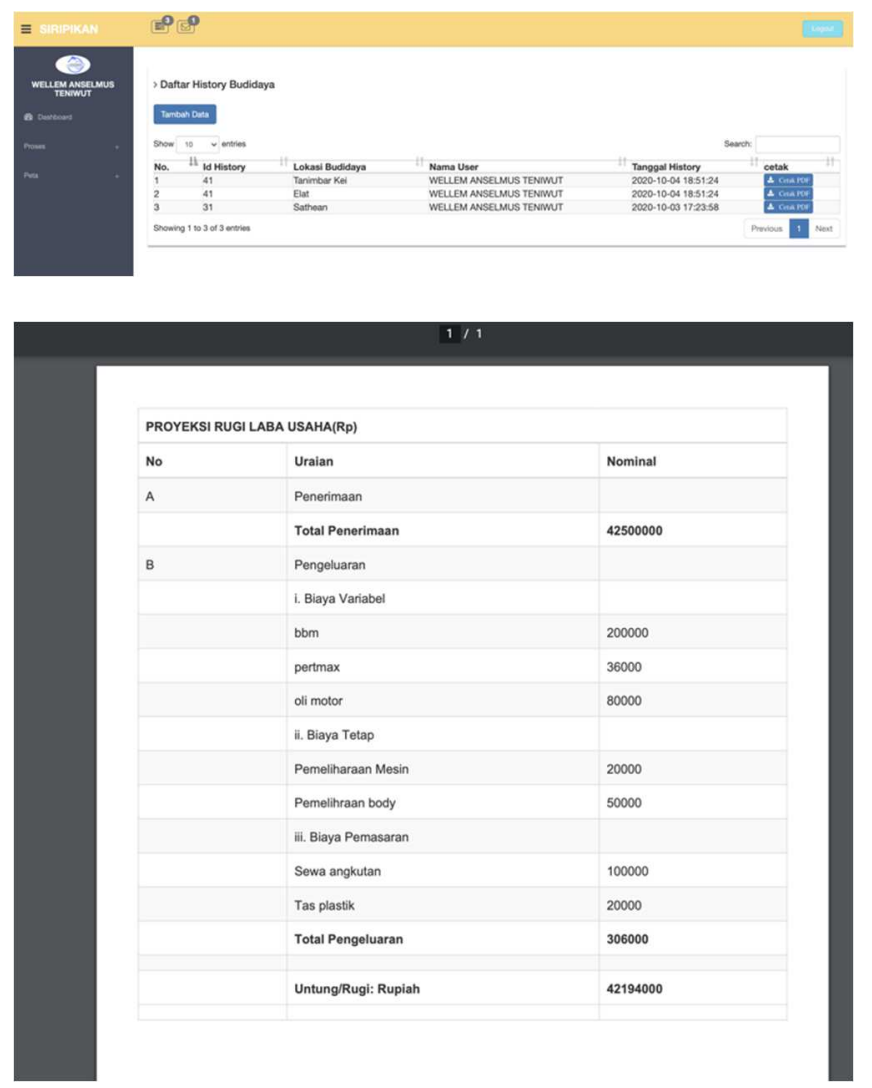

Fig. 8 Feasibility financial result

The fisheries supply chain information system design in Southeast Maluku Regency plays significant roles in the fisheries sector, specifically in small islands. DSS development relies heavily on providing and facilitating coastal communities, thereby producing an easy and straightforward interface. The DSS system is associated with three main production functions: input, process, and output, while the supply chain consists of the upstream and downstream. Conversely, information on the location of capture and production inputs also includes the supplier data, which facilitates the fisheries businesses, such as coastal communities. This helps in making profitable decisions and maintains the level of sustainability of existing marine resources.

\section{CONCLUSIONS}

The study aims to build a web-based fishery supply chain information system using data mining and Spatial Analysis approaches. SIRIPIKAN was built according to the needs of the users where before it was built, an FGD was first conducted to obtain information on problems related to the supply chain and fishery production. Based on this information, we have succeeded in building SIRIPIKAN according to the user's needs and desires. To ensure user satisfaction, we have also customized the interface and interactions in SIPRIKAN to make it more user-friendly so that users who have a low level of formal education can easily operate SIRIPIKAN. The SIRIPIKAN application can be accessed by using a smartphone by the user via an internet connection. In this application, users can get information on fishing locations close to the user's village location so that they are more effective and efficient in carrying out fishing activities. This application also offers information on suppliers and producers of fishery products so that both fishermen and fisheries farmers and sellers can easily interact with each other, which positively impacts distribution costs and profits. Besides, SIRIPIKAN provides facilities for calculating production costs, revenues and projected business profits.

The prototype of SIRIPIKAN will be further verified more widely, and more optimal development is carried out so that it can be more stable and interactive for users. SIRIPIKAN has room to be better developed in accordance with technological developments such as the use of API (Application Programming Interface) in adding features offered to increase user satisfaction.

\section{ACKNOWLEDGMENT}

The authors are grateful to the Directorate of Research and Community Service, Ministry of Research and Technology, to fund this research under the 2019-2020 PTUPT (Penelitian Terapan Unggulan Perguruan Tinggi) scheme.

\section{REFERENCES}

[1] V. Mohagheghi, S. M. Mousavi, M. Mojtahedi, and S. Newton, "Evaluating large, high-technology project portfolios using a novel interval-valued Pythagorean fuzzy set framework: An automated crane project case study," Expert Syst. Appl., 2020, doi: 10.1016/j.eswa.2019.113007.

[2] S. Ma, Y. Zhang, J. Lv, Y. Ge, H. Yang, and L. Li, "Big data driven predictive production planning for energy-intensive manufacturing industries," Energy, 2020, doi: 10.1016/j.energy.2020.118320.

[3] M. K. C. S. Wijewickrama, N. Chileshe, R. Rameezdeen, and J. J. Ochoa, "Information sharing in reverse logistics supply chain of demolition waste: A systematic literature review," Journal of Cleaner Production. 2021, doi: 10.1016/j.jclepro.2020.124359.

[4] J. Wei, Y. Wang, and J. Lu, "Information sharing and sales patterns choice in a supply chain with product's greening improvement," $J$. Clean. Prod., 2021, doi: 10.1016/j.jclepro.2020.123704.

[5] P. Howson, "Building trust and equity in marine conservation and fisheries supply chain management with blockchain," Mar. Policy, 2020, doi: 10.1016/j.marpol.2020.103873.

[6] W. A. Teniwut, K. D. Betaubun, Marimin, and T. Djatna, "A conceptual mitigation model for asymmetric information of supply chain in seaweed cultivation," in IOP Conference Series: Earth and Environmental Science, 2017, vol. 89, no. 1, doi: 10.1088/17551315/89/1/012022.

[7] W. A. Teniwut, M. Marimin, and T. Djatna, "GIS-Based multi-criteria decision-making model for site selection of seaweed farming information centre: A lesson from small islands, Indonesia," Decis. Sci. Lett., vol. 8, pp. 137-150, 2019, doi: 10.5267/j.dsl.2018.8.001.

[8] W. A. Teniwut and R. M. K. Teniwut, "Minimizing the instability of seaweed cultivation productivity on rural coastal area : a case study from Indonesia," vol. 11, no. 1, pp. 259-271, 2018.

[9] W. A. Teniwut, Y. K. Teniwut, R. M. K. Teniwut, and C. L. Hasyim, "Family vs Village-Based: Intangible View on the Sustainable of Seaweed Farming," IOP Conf. Ser. Earth Environ. Sci., vol. 89, no. 1, p. 012021 , Oct. 2017, doi: 10.1088/1755-1315/89/1/012021.

[10] W. A. Teniwut, "For sustainable revenue of fisheries sector in small islands: Evidence of Maluku, Indonesia," AACL Bioflux, 2016, doi: 10.5281/zenodo. 245507.

[11] Y. Yun, D. Ma, and M. Yang, "Human-computer interaction-based Decision Support System with Applications in Data Mining," Futur. Gener. Comput. Syst., 2021, doi: 10.1016/j.future.2020.07.048.

[12] W. Deng, L. Feng, X. Zhao, and Y. Lou, "Effects of supply chain competition on firms' product sustainability strategy," J. Clean. Prod., 2020, doi: 10.1016/j.jclepro.2020.124061. 
[13] J. Wang and W. Zhuo, "Strategic information sharing in a supply chain under potential supplier encroachment," Comput. Ind. Eng., 2020, doi: 10.1016/j.cie.2020.106880

[14] Y. Wang and S. H. Zhang, "Optimal production and inventory rationing policies with selective-information sharing and two demand classes," Eur. J. Oper. Res., 2021, doi: 10.1016/j.ejor.2020.05.051.

[15] J. Mar-Ortiz, M. D. Gracia, and N. Castillo-García, "Challenges in the design of decision support systems for port and maritime supply chains," in Studies in Computational Intelligence, 2018.

[16] G. Dellino, T. Laudadio, R. Mari, N. Mastronardi, and C. Meloni, "A reliable decision support system for fresh food supply chain management," Int. J. Prod. Res., 2018, doi: 10.1080/00207543.2017.1367106.

[17] F. Geri, S. Sacchelli, I. Bernetti, and M. Ciolli, Urban-rural bioenergy planning as a strategy for the sustainable development of inner areas: A GIS-based method to chance the forest chain, no. 9783319757. 2018.

[18] M. Dev, P. Kaur, and K. K. Sarma, "Fuzzy Approach to Decision Support System Design for Inventory Control and Management," $J$. Intell. Syst., 2017, doi: 10.1515/jisys-2017-0143.

[19] M. Chica and W. Rand, "Building agent-based decision support systems for word-of-mouth programs: A freemium application," $J$. Mark. Res., 2017, doi: 10.1509/jmr.15.0443.

[20] Marimin, W. Adhi, and M. A. Darmawan, "Decision support system for natural rubber supply chain management performance measurement: A sustainable balanced scorecard approach," Int. J. Supply Chain Manag., 2017.

[21] G. Dutta, N. Gupta, J. Mandal, and M. K. Tiwari, "New decision support system for strategic planning in process industries: Computational results," Comput. Ind. Eng., 2018, doi: 10.1016/j.cie.2018.07.016.

[22] P. K. Tarei, J. J. Thakkar, and B. Nag, "Development of a decision support system for assessing the supply chain risk mitigation strategies: an application in Indian petroleum supply chain," J. Manuf. Technol. Manag., 2020, doi: 10.1108/JMTM-02-2020-0035.

[23] M. Alkahtani, A. Choudhary, A. De, and J. A. Harding, "A decision support system based on ontology and data mining to improve design using warranty data," Comput. Ind. Eng., 2019, doi: 10.1016/j.cie.2018.04.033.

[24] H. Talebian, O. E. Herrera, and W. Mérida, "Spatial and temporal optimization of hydrogen fuel supply chain for light duty passenger vehicles in British Columbia," Int. J. Hydrogen Energy, 2019, doi: 10.1016/j.ijhydene.2019.07.218.
[25] E. P. Sarabi and S. A. Darestani, "Developing a decision support system for logistics service provider selection employing fuzzy MULTIMOORA \& BWM in mining equipment manufacturing," Appl. Soft Comput., 2020, doi: 10.1016/j.asoc.2020.106849.

[26] B. Imène and T. Noria, "Towards a new supporting platform for collaboration in industrial diagnosis within an agent-based WEB DSS," Int. J. Comput. Aided Eng. Technol., 2018, doi: 10.1504/IJCAET.2018.092865.

[27] H. Allaoui, Y. Guo, and J. Sarkis, "Decision support for collaboration planning in sustainable supply chains," J. Clean. Prod., 2019, doi: 10.1016/j.jclepro.2019.04.367

[28] M. Yazdani, P. Zarate, A. Coulibaly, and E. K. Zavadskas, “A group decision making support system in logistics and supply chain management," Expert Syst. Appl., vol. 88, pp. 376-392, 2017, doi: 10.1016/j.eswa.2017.07.014

[29] G. Im and A. Rai, "IT-enabled coordination for ambidextrous interorganizational relationships," Inf. Syst. Res., 2014, doi: 10.1287/isre.2013.0496.

[30] J. Xin, "A supply chain optimization DSS Web-services-based for eretail industry," 2011, doi: 10.1109/PEAM.2011.6135052.

[31] A. Bonfante et al., "LCIS DSS - An irrigation supporting system for water use efficiency improvement in precision agriculture: A maize case study," Agric. Syst., 2019, doi: 10.1016/j.agsy.2019.102646.

[32] K. L. Carder, F. R. Chen, Z. Lee, S. K. Hawes, and J. P. Cannizzaro, MODIS Ocean Science Team Algorithm Theoretical Basis Document ATBD 19: Case 2 Chlorophyll a. 2003.

[33] O. B. Brown and P. J. Minnett, "MODIS infrared sea surface temperature algorithm - Algorithm Theoretical Basis Document Version 2.0," 1999.

[34] N. Zendrato, H. W. Dhany, N. A. Siagian, and F. Izhari, "Bigdata Clustering using X-means method with Euclidean Distance,” 2020, doi: 10.1088/1742-6596/1566/1/012103.

[35] O. Stavrakidis-Zachou, N. Papandroulakis, A. Sturm, P. Anastasiadis, F. Wätzold, and K. Lika, "Towards a computer-based decision support system for aquaculture stakeholders in Greece in the context of climate change," 2018, doi: 10.1504/IJSAMI.2018.099235.

[36] Á. Cobo, I. Llorente, L. Luna, and M. Luna, "A decision support system for fish farming using particle swarm optimization," Comput. Electron. Agric., 2019, doi: 10.1016/j.compag.2018.03.036. 